\title{
Molecular and Phenotypic Characterization of Novel Streptomyces Species Isolated from Kurdistan Soil and its Antibacterial Activity Against Human Pathogens
}

\author{
Bayan Kakamand Jalal, Ayad H. Hasan* \\ ${ }^{1}$ Department of Medical Microbiology, Faculty of Science and Health, Koya University, Koya KOY45, Kurdistan Region - F.R. Iraq
}

Received: July 14, 2020; Revised: October 27, 2020; Accepted: November 7, 2020

\begin{abstract}
The rise in antibiotic resistance globally has expedited the search for novel antibiotics. Streptomycetaceae are the producer of more than $70 \%$ of clinical antibiotics; researchers have been shedding light on the genus Streptomyces in hope of discovering novel species with the ability to produce effective and efficient molecules against superbugs. This study aims to investigate different sources of Kurdistan soil for the existence of novel Streptomyces species that possess bioactive compounds. So, twenty soil samples were obtained from agricultural soil, house garden soil, cave soil, and soil contaminated with petroleum. Selective media combined with morphological characterisation, biochemical tests and molecular techniques were used for species identification. Only fifty-eight bacterial samples were given a positive PCR product in which thirtyone 16S rDNA sequences were compared with previously existed prokaryotic DNA sequences using the EzTaxon database. Twenty-nine out of thirty-one samples showed $>99 \%$ similarity to previously cultured Streptomyces spp. and two isolates from house garden soil samples were candidates to be novel species, and they have shown antibacterial activity against $E$. coli (ATCC 25218) and Staphylococcus aureus (ATCC 25923) by inhibiting their growth on Mueller-Hinton agar plate using cross streak method.
\end{abstract}

Keywords: Streptomyces, Soil, 16S rDNA, Phylogenetic tree

\section{Introduction}

The genus Streptomyces is well-known for producing plenty of bioactive specialized metabolites with advantageous applications in clinical, veterinary, and agriculture settings (Li et al., 2019), such as antifungal, antibacterial, anticancer, and anthelmintic drugs (Janardhan et al., 2014; Chen et al., 2018).

This enormous resource of diverse compounds puts Streptomyces at the top of medically important microbial genera (George et al., 2010). In addition, it has a number of important functions, including degradation/ decomposition of all sorts of organic substances such as cellulose, polysaccharides, protein fats, and organic acids, they have a great role in the subsequent decomposing of humus (resistant material) in soil (Anandan et al., 2016). It is also responsible for the distinctive earthy odor of freshly ploughed soil caused by geosmin production (Adegboye and Babalola, 2012).

The rapid emergence of antimicrobial resistance in bacterial and fungal pathogens is a public health crisis (Chevrette et al., 2019). For instance, the clinical bacterial strain methicillin-resistant Staphylococcus aureus (MRSA) has been designated as one of the major hazardous pathogens associated with the development of antimicrobial resistance (AMR), along with the other clinical strain vancomycin-resistant Enterococcus faecium (VRE) (Yücel and Yamaç, 2010; Walker et al., 2019) and

\footnotetext{
* Corresponding author e-mail: : ayad.hasan@koyauniversity.org.
}

Pseudomonas aeruginosa that are resistant to even last resort antibiotics (Murray et al., 2019). Novel antibacterial molecules are necessary to fight against pathogens that have advanced resistance against current antibiotics (Fatima et al., 2019; Sottorff et al., 2019). So, researchers are eagerly searching for a novel, sustainable, potent, and broad-spectrum antimicrobial compounds from various sources, including microbes in natural soil habitats. Many known species of Streptomyces with antibacterial and antifungal activities were identified in the past decade during Iraqi soil investigation for novel species of actinomycetes (Al-Hulu et al., 2011; Laidi et al., 2013). However, to the best of our knowledge, no one targeted Kurdistan soil to isolate Streptomyces spp. So, based on that and considering, Streptomyces as prolific producers of useful bioactive compounds (Singh et al., 2016), this study was aimed to isolate and identify new species of Streptomyces from the soil of Kurdistan Region in Iraq then test its secondary metabolites activities toward exemplary of gram positive and negative pathogenic bacteria.

\section{Materials and Methods}

\subsection{Sample Collection}

Several diverse habitats in Kurdistan Region-Iraq $\left(36.4103^{\circ} \mathrm{N}, 44.3872^{\circ} \mathrm{E}\right)$ were chosen to increase the chances of finding new species. Between October and November 2018 twenty samples from each of the 
following locations were collected; Jgila-Kirkuk

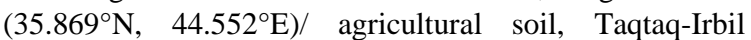
$\left(35.915^{\circ} \mathrm{N}, 44.490^{\circ} \mathrm{E}\right) /$ house garden soil, Kanylala $\left(35.886^{\circ} \mathrm{N}, 44.583^{\circ} \mathrm{E}\right) /$ cave soil, and Barhushtr-Irbil $\left(36.350^{\circ} \mathrm{N}, 43.888^{\circ} \mathrm{E}\right) /$ petroleum soil. The samples were collected from down to $15 \mathrm{~cm}$ depth after discarding 3.0 $\mathrm{cm}$ of soil surface. Polyethylene bags were used to collect about $5 \mathrm{gm}$ of the soil samples then sealed and immediately transported to the laboratory. Then, the soil was kept at $4^{\circ} \mathrm{C}$ until the time of processing. To provide a $\mathrm{pH}$ condition similar to the original habitat of the taken samples, the soil's pH was measured as follows; 50 gm of soil from each location was suspended in $100 \mathrm{ml}$ of distilled water and vortexed and incubated for $30 \mathrm{~min}$ at $20^{\circ} \mathrm{C}$ then filtrated using Whatman filter paper No. 1 . Then the supernatant pH was measured by pH meter (HI 2211 $\mathrm{Ph} / \mathrm{ORP}$ Meter, Italy) (Massadeh and Mahmoud., 2019).

\subsubsection{Isolation of Streptomyces spp.}

The collected soil samples were prepared as follows: 5 gm of soil from each sample was added to $45 \mathrm{ml}$ distilled water in a $250 \mathrm{ml}$ Pyrex bottle under sterile condition and incubated at room temperature for 30 min with shaking (120 rpm) (shaker incubator GFL, Germany). $1 \mathrm{ml}$ from each sample supernatant was serially diluted up to $10^{-3}$ dilutions, then aliquot of $100 \mu \mathrm{l}$ from each dilution was spread over International Streptomyces project medium No. 4 (ISP4) agar plates contain ampicillin and nystatin at a final concentration of $25 \mu \mathrm{g} / \mathrm{ml}$ and $50 \mu \mathrm{g} / \mathrm{ml}$, respectively (Chen et al., 2018). All the cultured plates were incubated at $28^{\circ} \mathrm{C}$ in aerobic condition for 5 days. After incubation, Streptomyces look alike colonies were selected according to their phenotype and subjected to pure culture technique (George et al., 2010; Maleki et al., 2013).

\subsubsection{Cultural Purification and Spore Stocks Preparation:}

A single colony from each grown plate in section 2.1.1 was streaked on ISP4 agar plates and incubated at $28^{\circ} \mathrm{C}$ for 5 days. Then the single isolated colonies were characterised based on the colony pigmentation and Streptomyces morphological appearance (Arifuzzaman et al., 2010). To store the bacterial strains for long term and be used when needed, a Mannitol Soya Flour medium (MSF) was used for this purpose. Then $20 \%$ glycerol spore stocks of suspected Streptomyces spp. were prepared according to Kim et al. (2015) and stored at $-80^{\circ} \mathrm{C}$ which can remain viable for several years even after multiple freeze-thaw cycles (Shepherd et al., 2010).

\subsubsection{Gram Stain and Biochemical Tests}

Standard Gram stain was carried out on the bacterial isolates and visualized under a compound microscope at $\mathrm{X} 100$. At the same time, they were subjected to the following biochemical tests: catalase test, citrate utilization test, indole production test, and melanin production. Streptomyces coelicolor M15 was used as a positive control.

\subsubsection{Phenotypic Characterisation}

$40 \mathrm{ml}$ of Yeast Extract-Malt Extract medium (YEME) supplemented with $50 \mu \mathrm{g} / \mathrm{ml}$ ampicillin in $250 \mathrm{ml}$ Pyrex bottle was inoculated with the bacterial isolate to be examined; all the inoculated bottles were incubated for 3 to 5 days with shaking at $220 \mathrm{rpm} 20 \mu \mathrm{l}$ from each cultured strain was spotted onto Tryptone Soya Agar (TSA). All plates were incubated for 5 days before being photographed at this point every 24 hrs for the next 120 hrs. Morphological observations through macromorphology were based on the growth pattern on the TSA medium. The colour of Streptomyces colonies and soluble pigment was observed by the naked eye.

\subsection{Molecular identification}

\subsubsection{Strain Preparation for Genomic DNA Extraction}

To extract genomic DNA from each bacterial isolate individually, $40 \mathrm{ml}$ of YEME supplemented with $50 \mu \mathrm{g} / \mathrm{ml}$ ampicillin in a Pyrex bottle (250 ml volume) was inoculated with an appropriate amount of certain Streptomyces spores. The Pyrex bottle was fitted with glass beads for better aeration and to break up mycelium clump. All bottles were incubated at $28^{\circ} \mathrm{C}$ with shaking at $220 \mathrm{rpm}$ for $72 \mathrm{hrs}$ or up to $96 \mathrm{hrs}$ for the slow growing isolate (Minas et al., 2000).

After the incubation period, the $40 \mathrm{ml}$ culture was transferred into a $50 \mathrm{ml}$ Falcon tube, centrifuged at 13000 rpm (Cooling Centrifuge 3-30K Sigma 147101, Germany) for $10 \mathrm{~min}$ The cell pellet was washed with $10 \mathrm{ml}$ sterilised D.W and re-harvested then subjected to DNA extraction according to Romero et al. (2014). The cell pellet was resuspended in $10 \mathrm{ml}$ of $1 \mathrm{M}$ TE buffer (pH 8) containing 20 $\mathrm{mg} / \mathrm{ml}$ lysozyme then incubated at $37^{\circ} \mathrm{C}$ for $1 \mathrm{hr}$. SDS and $\mathrm{NaCl}$ were added to final concentrations of $0.5 \%[\mathrm{w} / \mathrm{v}]$ and $150 \mathrm{mM}$, respectively. The tube was added to a boilingwater bath for $1 \mathrm{~min}$ after brief vortexing and then placed in ice to cool down. An equal volume of phenol $\mathrm{pH} 8$ (buffer-saturated) was added, and the mixture was vortexed. The cell debris was separated from the cell lysate at room temperature by centrifugation at $13000 \mathrm{rpm}$ for 10 min For further extraction as described for the phenol, the supernatant was moved to a new Eppendorf tube containing an equal volume of phenol ( $\mathrm{pH}$ 8): chloroform: isoamyl alcohol (25:24:1) extraction. The extraction was then repeated using chloroform: isoamyl alcohol (49:1). The resulting aqueous phase was transferred to new tubes and a 2.5 volume of absolute ethanol was added to each. Sodium chloride was added to its final concentration (150 $\mathrm{mM}$ ) and the tube was incubated for $30 \mathrm{~min}$ at $-20^{\circ} \mathrm{C}$. The precipitate genomic DNA was collected at $4^{\circ} \mathrm{C}$ by centrifugation for $30 \mathrm{~min}$ at $13000 \mathrm{rpm}$ The harvested pellet was washed with $70 \%(\mathrm{v} / \mathrm{v})$ ethanol then resuspended in nuclease free D.W to be stored at $-20^{\circ} \mathrm{C}$.

\subsubsection{Standard PCR Amplification of $16 S$ rRNA Genes}

Partial amplification of 16S rRNA genes was performed using Prime Taq premix PCR Master Mix (2X) kit. All amplification reactions were performed in a final volume of $40 \mu \mathrm{l}$ of PCR reaction mixture which included $20 \mu \mathrm{l}$ of $2 \mathrm{X}$ prime Taq premix, $10 \mathrm{pmol}(2 \mu \mathrm{l})$ of forward (FWD) and reverse (REV) primers. StrepB (FWD) and StrepF (REV) primers were used to amplify the 16S rRNA gene partially with an end product size of $1074 \mathrm{bp}$ (see Table 1), $100 \mathrm{ng}(1 \mu \mathrm{l})$ template DNA, and $15 \mu \mathrm{l}$ DEPC treated D.W or nuclease-free water were added for each reaction. The PCR process was performed using BIO RAD T100TM Thermal Cycler (UK) and programmed as follows: 5 min of initial denaturation at $98^{\circ} \mathrm{C}$, followed by 25 cycles of reaction with $30 \mathrm{~s}$ of denaturing at $98^{\circ} \mathrm{C}, 30 \mathrm{~s}$ of annealing at $59^{\circ} \mathrm{C}, 45 \mathrm{~s}$ of extension at $72^{\circ} \mathrm{C}$, and the final extension was performed for $5 \mathrm{~min}$ at $72^{\circ} \mathrm{C}$. 
Table 1. Names, target gene, sequences, size, binding site, and annealing temperature of primers used in this study.

\begin{tabular}{lllcc}
\hline Primer Name & Target Gene & Sequence $\left.(5,>>>>>3)^{*}\right)$ & Size (bp) & Position** \\
& & & \\
\hline StrepB (FWD) & 16S rRNA & ACAAGCCCTGGAAACGGGGT & 1074 & $139-158$ \\
StrepF (REV) & & ACGTGTGCAGCCCAAGACA & $1194-1212$ \\
\hline
\end{tabular}

* The 16S RNA gene primers sequence were taken from (Rintala et al., 2001). ** Reference to the 16s rRNA genes in Streptomyces coelicolor.

\subsubsection{Gel Electrophoresis Analysis}

To confirm that a correct size of the targeted gene was amplified, an aliquot of $2 \mu \mathrm{l}$ of PCR reaction products was electrophoresed on a $1 \%$ agarose gel containing ethidium bromide $(0.5 \mu \mathrm{g} / \mathrm{ml})$ along with 100bp DNA marker (Amresco DNA MW Marker 100bp) and ran in 1X TBE buffer at $85 \mathrm{~V}$ for 1:15 hrs. After the course of running, the DNA bands were visualized and photographed using (UV Gel Imager SynGene 1409) (Abdullah et al., 2017).

\subsection{Sequencing of The 16S rRNA Gene Amplicons}

The resulted PCR products were sent out for sequencing, after size confirmation. The sequencing was carried out by (Macrogen Inc, a South Korean company) using StrepF for partial 16S rRNA gene sequencing.

\subsubsection{Sequence Quality and Length}

Sequence analysis and editing were performed using DNA Baser Assembler. In order to perform quality trimming, the start and end of the sequences were trimmed when more than $80 \%$ good bases in a 20 bases window were found. After trimming, the sample was counted as low quality when less than $90 \%$ of the bases with less than 25 quality values (QV) were detected. The sequence samples were considered good when over $90 \%$ of the bases have QV over 25. When the size of the remaining DNA segment after trimming was shorter than 600bp, the sample was discarded.

\subsubsection{Novel Species Identification}

To identify the isolated bacterial samples individually, the 16S rRNA genes query sequence was compared with previously existed prokaryotic DNA sequences using the EzTaxon database (Yoon et al., 2017). In order to detect novel strains of Streptomyces the following criteria were applied: candidate for uncultured species (similarity threshold between $98.7 \%$ and $99.0 \%$ ), genera (95.3$90.0 \%$ ) or family ( $<90.0 \%)$, $>99 \%$ similarity considered as same species (Stackebrandt and Ebers, 2006; Schlaberg et al., 2012). For strains with no similar sequences, the data were deposited in the GenBank database using the following website "http://www.ncbi.nlm.nih.gov/BankIt".

\subsection{Phylogenetic Analysis}

The sequences of new Streptomyces spp. candidate were aligned against the sequence of all species of Streptomyces that came up after comparison search using Clustal W (Thompson et al., 1994). The Neighbor-joining (NJ) method was used to find out the phylogenetic tree using Molecular Evolutionary Genetics Analysis (MEGAX) software (Saitou and Nei, 1987; Tamura et al., 2011).

\subsection{Antibacterial Activity of Secondary Metabolites}

In order to screen the antibacterial activities of Streptomyces spp. secondary metabolites, a straight line was drawn by a loopful of certain Streptomyces bacterial colony from one side of Mueller-Hinton agar plate to the other side across the center (Alabi et al., 2019). After seven days of incubation at $28^{\circ} \mathrm{C}$, one side of the grown line was inoculated by a single streak of $E$. coli (ATCC 25218) and the other side was inoculated by Staphylococcus aureus (ATCC 25923) at a 90-degree angle toward the grown line of Streptomyces spp. then the plates were incubated at $37^{\circ} \mathrm{C}$ for 24 hrs. For comparison, positive and negative controls were set up using Streptomyces coelicolor L646 strain and Streptomyces spp. free Mueller-Hinton agar plate inoculated with $E$. coil and Staphylococcus aureus, respectively. This experiment was performed in triplicate and the antimicrobial activity was observed by the naked eye.

\section{Results and Discussion}

\subsection{Sample Collection, Bacterial Isolation and Purification}

In total, 68 bacterial entities were detected from 80 soil samples that were collected from different areas of Kurdistan Region-Iraq. The soil samples were collected specifically from agricultural and house garden soil where a great component of roots organic compounds exudate is available, which in turn can promote differential recruitment of actinomycetes (Massenssini et al., 2014), cave soil with manure where the composition of manure such as carbon and other organic materials increases the rate of soil respiration and microbial activity which lead to increase the functional diversity of microbial biomass (Adebola et al., 2017) and petroleum soil where petroleum inhibits and reduces species member of a microbial community; thus few of them govern the community such as Pseudomonas and Streptomyces (Xu et al., 2018).

The $\mathrm{pH}$ of the soil was between $(7.5-7.8)$ for all the locations that have been examined. As known, soil provides a suitable environment for many bacterial genus and fungi to grow, so in order to inhibit their growth ISP4 media was used which is a selective media supplemented with nystatin that inhibits fungal growth and ampicillin that suppresses the growth of a wide range of bacteria (Awad and Germoush, 2017).

In general, Streptomyces colonies show powdery consistency and stick firmly to the ISP4 agar surface, producing hyphae and conidia/ sporangia-like fungi (Anandan et al., 2016). Colonies were relatively smooth surfaced, but later they developed a weft of aerial mycelium that appeared floccose, granular, powdery, and 
velvety coloured white or grey with a white ring (Ambarwati et al., 2012).

Although every grown single colony on ISP4 may be counted as Streptomyces, only those that expressed typical Streptomyces morphology have been isolated from the collected samples and subjected to pure culture technique (Hasani et al., 2014). So, a colony with Streptomyces look alike morphology was re-streaked out on the ISP4 agar plate contains nystatin and ampicillin. After 5 days of incubation, they produced a wide variety of pigments such as white, grey with a white ring, grey, red, yellow, blue, purple, and pink, which are responsible for the colour of the vegetative and aerial mycelia (see Lane A in Figures 1, 2, 3 and 4) (Flärdh and Buttner, 2009). The spores were grown on MSF with different colour characteristics such as grey with various shades, white, dark green, pink, yellow, brown, purple, purple-red, a black centered colony with a white edge, and pale blue after five days of incubation at $28^{\circ} \mathrm{C}$ (see Lane B in Figures 1, 2, 3 and 4). Some strains had slow growth properties that took more than 10 days to produce spores and pigmentation; those were AS18-3, HGS5-3, HGS5-5, HGS7-2, HGS8-3, HGS13-2, HGS141, CS12, PS5-2, and PS13. Observed growth status appeared to be in the scope of Streptomyces slow growing properties with their limited resource of nutrition (Westhoff et al., 2020). For future work, these strains can be compared with the reported from the literature to check if this behavior (slow growth) is common. The most dominant colours in the population of sporulation process have been assigned to two groups: grey with different shades and brown; however, unique pigments were detected as well such as green, blue and purple. Streptomyces spp. spore pigmentation is the result of polyketide synthesis regulated by whi genes that are responsible for the production of polyketide type II components such as tetracenomycin, granaticin, oxytetracycline, and actinorhodin (Kelemen et al., 1998; Salerno et al., 2013).

\subsection{Bacterial Identification}

\subsubsection{Microscopic Characterisation and Biochemical Tests}

Streptomyces isolates were found as long filamentous gram-positive bacteria when examined by compound microscope at X1000 magnification. According to the biochemical tests that were carried out to identify the isolated strains, all the isolates including $S$. coelicolor M145 were found to be positive for catalase and citrate utilization tests and negative for indole and melanin productions.

\subsubsection{Phenotypic Characteristics}

Streptomyces is well known for its ability to produce a wide range of pigments that colour the aerial spore mass and vegetative and aerial mycelia. This ability has been used to identify the genus of Streptomyces, and in fact, it was the only character used in many early descriptions (Al-Saadi et al., 2013). So, in this study pigment production during isolation (on ISP4), sporulation, and vegetative stage were adopted as a primitive method to determine the phenotype of certain bacterial strains after being cultured on MSF agar for sporulation and TSA agar for mycelial growth. Spore's colour was determined during spore stock preparation on MSF, which was mentioned previously.

Actinomycetes produce many types of antibiotics that have pigments and can be detected in artificial media; these pigments are commonly defined in different colours (Kheiralla et al., 2016). The colours and nature of the pigments are varied depending on the type of nitrogen and carbon sources present in the media (Reddy and Umamaheshwara, 2016) and are also affected by incubation temperature, aeration, and initial medium $\mathrm{pH}$ (Kheiralla et al., 2016). In order to examine the ability of purified bacterial samples to produce secondary metabolite (SM), $20 \mu \mathrm{l}$ of fresh bacterial culture in YEME was spotted as a patch on TSA agar in triplicate and incubated for five days at $28^{\circ} \mathrm{C}$. The bacterial isolates were assigned to six colour series: white, pink, yellow, grey, pale grey, and brown. Surprisingly, a group of four bacterial isolates did not grow on TSA agar plates which can be due to the limitation of some crucial nutrients and elements or inadequate incubation temperatures or $\mathrm{pH}$ conditions or the growth might have been inhibited by antibacterial substances present within the medium. For future work, we will try to change these conditions and check for growth (see Lane C in Figures 1, 2, 3 and 4) (Vartoukian et al., 2010). 


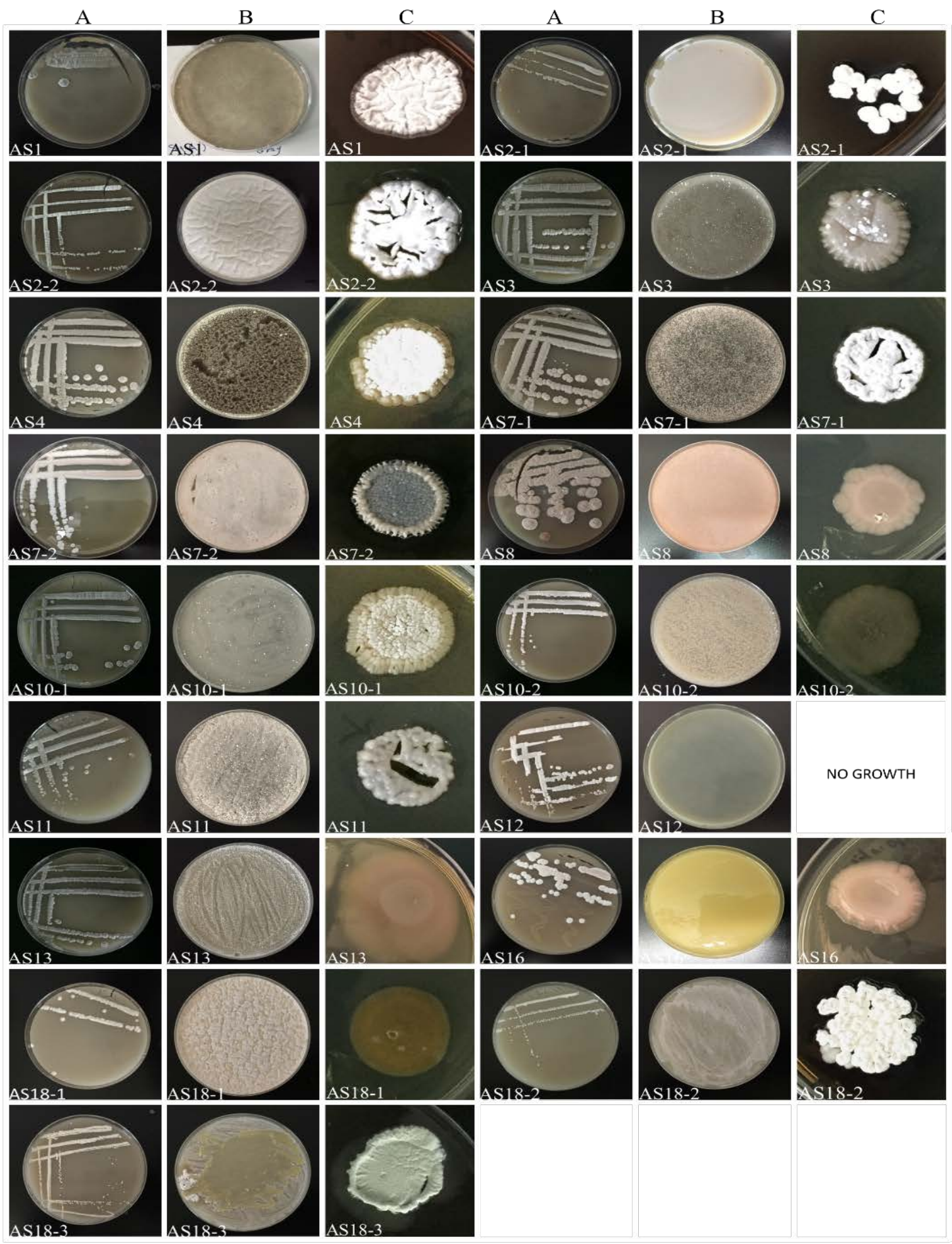

Figure 1. Colour and morphology of Streptomyces spp. that are isolated from agricultural soil. The names have been abbreviated to include A (agriculture) S (soil) followed by the sample number. Lane A shows a pure culture process. A single bacterial colony from the original soil sample was streaked on ISP4 agar plates. Lane B shows spore formation on MSF agar plates. Lane C shows patches of colour for each bacterial isolate on TSA plates. All the plates were incubated at $28^{\circ} \mathrm{C}$ for five days. 


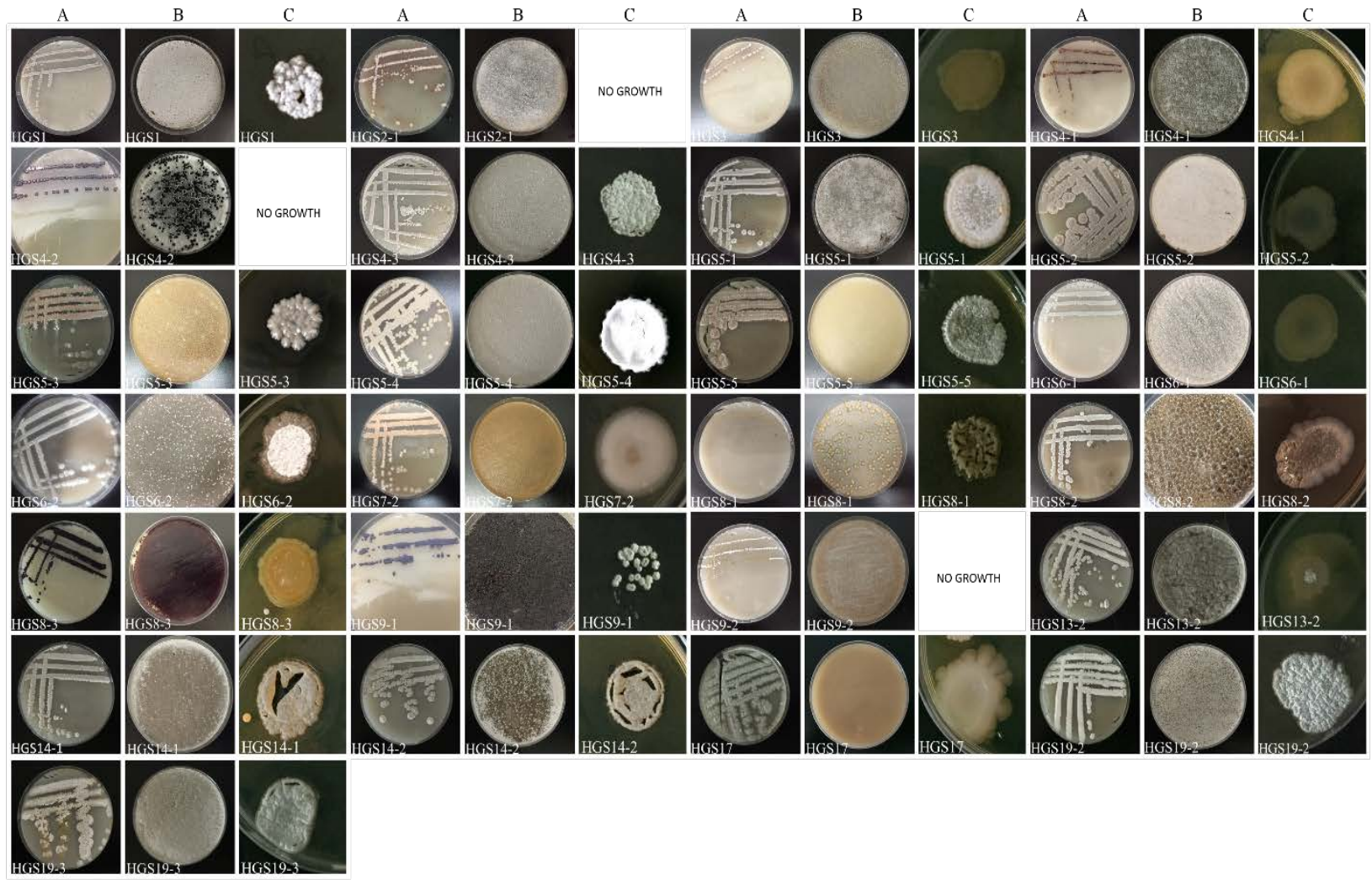

Figure 2. Colour and morphology of Streptomyces spp. that are isolated from house garden soil. The names have been abbreviated to include HG (house garden) S (soil) followed by the sample number. Lane A shows a pure culture process. A single bacterial colony from the original soil sample was streaked on ISP4 agar plates. Lane B shows spore formation on MSF agar plates. Lane C shows patches of colour for each bacterial isolate on TSA plates. All the plates were incubated at $28^{\circ} \mathrm{C}$ for five days.

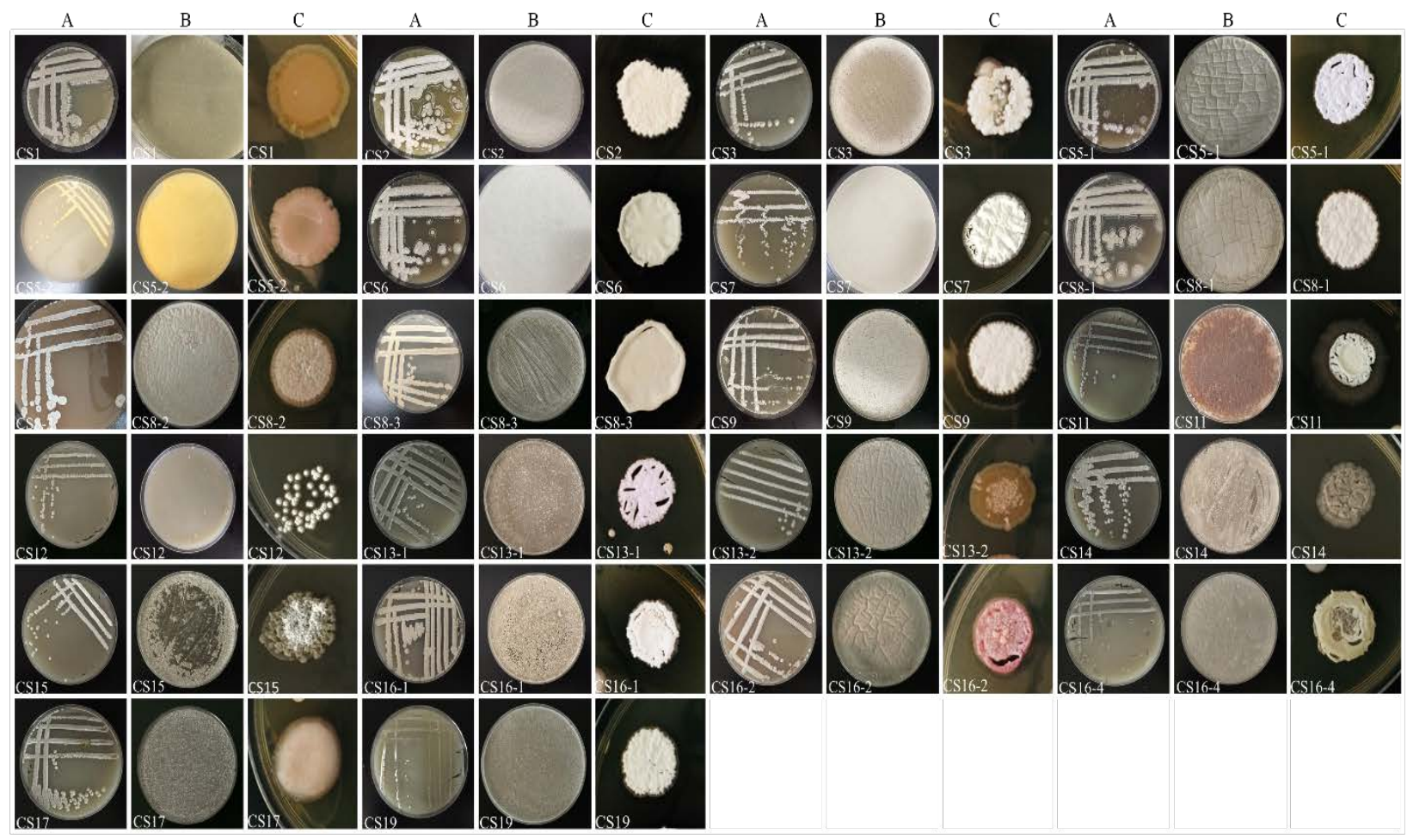

Figure 3. Colour and morphology of Streptomyces spp. that isolated are from cave soil. The names have been abbreviated to include C (cave) S (soil) followed by the sample number. Lane A shows a pure culture process. A single bacterial colony from the original soil sample was streaked on ISP4 agar plates. Lane B shows spore formation on MSF agar plates. Lane C shows patches of colour for each bacterial isolate on TSA plates. All the plates were incubated at $28^{\circ} \mathrm{C}$ for five days. 

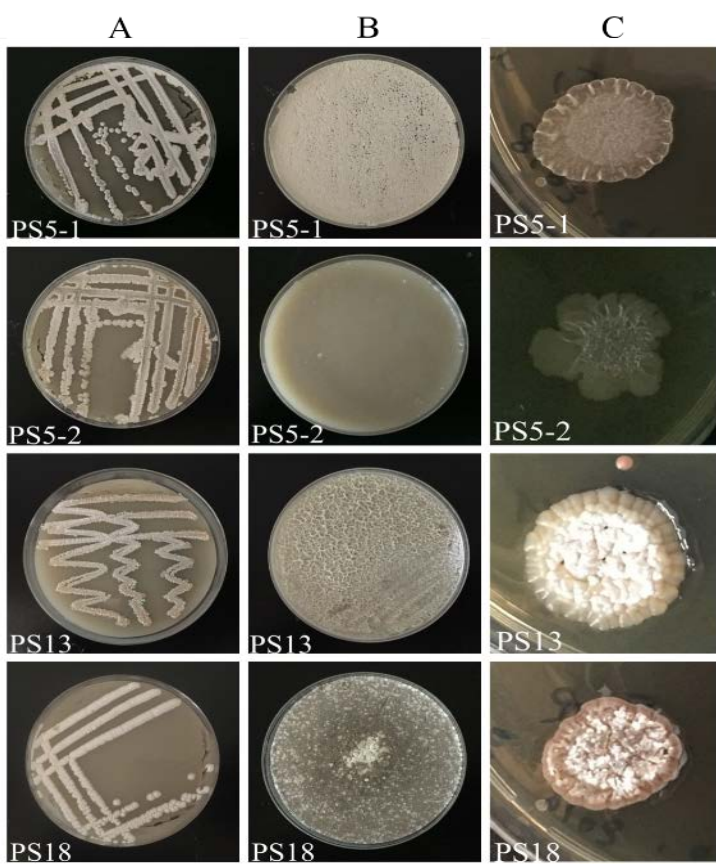

Figure 4. Colour and morphology of Streptomyces spp. that are isolated from petroleum contaminated soil. The names have been abbreviated to include $\mathrm{P}$ (petroleum) $\mathrm{S}$ (soil) followed by the sample number. Lane A shows a pure culture process. A single bacterial colony from the original soil sample was streaked on ISP4 agar plates. Lane B shows spore formation on MSF agar plates. Lane $\mathrm{C}$ shows patches of colour for each bacterial isolate on TSA plates. All the plates were incubated at $28^{\circ} \mathrm{C}$ for five days.

\subsubsection{Molecular Characteristics}

The expected size of DNA fragment (1074bp) was amplified successfully from template DNA isolated from the positive control Streptomyces coelicolor M145 and 58 out of 68 bacterial isolates. No PCR products were detected in the negative control and the remaining 10 bacterial samples (see Figure 5).

To track down each bacterial isolate to its exact species, the 16S rRNA gene PCR amplicons of each isolate were sent out for sequencing using the reverse primer StrepF.

\subsection{Partial Sequencing of $16 S$ rRNA Gene and its Quality}

Based on the validity of the DNA sequencing, just 31 samples were considered for further investigation. The samples were AS1, AS3, AS7-1, AS7-2, AS10-1, AS10-2, AS11, AS12, AS13, AS18-1, AS18-3, HGS3, HGS4-1, HGS4-3, HGS5-1, HGS5-3, HGS5-5, HGS6-1, HGS9-1, HGS14-1, HGS19-3, CS2, CS7-1, CS8-1, CS12, CS13-1, CS16-4, CS17, CS19, PS5-2, and PS13.

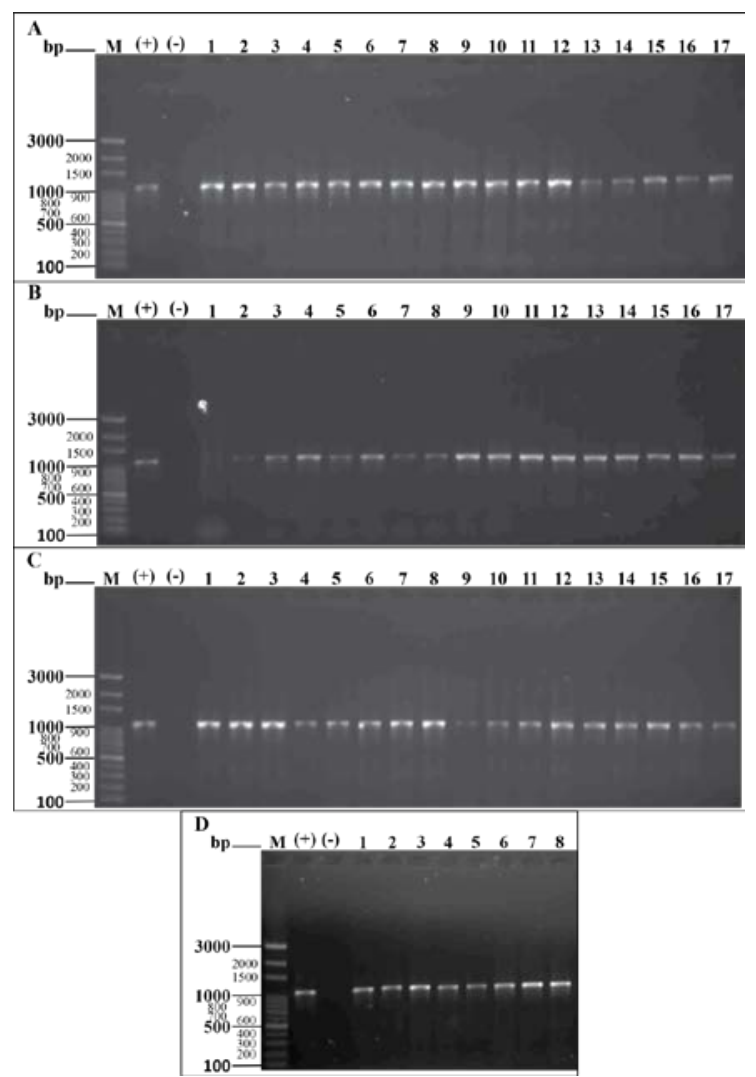

Figure 5. Genomic DNA amplification using StrepB and StrepF primer pairs that target $16 \mathrm{~S}$ rRNA gene (1074bp). Lanes $\mathrm{M},+\mathrm{V}$, and $-\mathrm{V}$ corresponds to the 100bp DNA ladder (Amresco DNA MW Marker 100bp), positive control that contained DNA template from Streptomyces coelicolor M145 and negative control that has been run without any DNA template, respectively. The bands are showing 1074bp of PCR amplicons. Panel A Lanes 1 to 17 contain PCR products from AS1, AS2-2, AS3, AS4, AS7-1, AS7-2, AS10-1, AS10-2, AS11, AS12, AS13, AS18-1, AS18-3, HGS1, HGS3, HGS4-1, and HGS4-3, respectively. Panel B Lanes 2 to 17 contain PCR products from HGS5-1, HGS5-2, HGS5-3, HGS5-4, HGS5-5, HGS6-1, HGS6-2, HGS7-2, HGS8-1, HGS8-2, HGS8-3, HGS9-1, HGS13-2, HGS14-1, HGS14-2, and HGS19-2, respectively. Panel C Lanes 1 to 17 contain PCR products from HGS19-3, CS1, CS2, CS3, CS5-1, CS5-2, CS6, CS7-1, CS8-1, CS8-2, CS9, CS11, CS12, CS13-1, CS13-2, CS14, and CS15, respectively. Panel D Lanes 1 to 8 contain PCR products from CS16-2, CS16-4, CS17, CS19, PS5-1, PS5-2, PS13, and PS18, respectively.

\subsection{Uncultured Species}

To analyse the taxonomic position of the 31 good quality 16S rDNA samples, individual automated alignment was conducted using EZBioCloud (Yoon et al., 2017) against available bacterial 16S rDNA sequences. The samples were identified through sequence pairwisesimilarity based on the criteria mentioned in section (2.3.2). A total of 29 samples showed $>99 \%$ similarity to previously cultured Streptomyces spp., so no further investigation was conducted on them. The remaining two isolates from house garden soil HGS6-1 and HGS19-3 showed $98.8 \%$ and $98.9 \%$ similarity to their top hit, which were Streptomyces nigra and Streptomyces albogriseolus, respectively. This percentage of similarity and mismatches candidate HGS6-1 and HGS19-3 isolates as uncultured species because the sequence identity value of their shared gene is located between $98.7 \%$ and $99 \%$ (Stackebrandt and 
Ebers, 2006). So, HGS6-1 and HGS19-3 isolates are considered to serve as novel species for which the name Streptomyces nigra strain BA1 and Streptomyces albogriseolus strain BA2 proposed, respectively.

Online multiple alignments (Huang and Miller, 1991) between S. nigra strain BA1 and S. nigra showed one gap and 7 mismatches at nucleotide positions 155, 166, 17, 193, 202, 08, 328, and 502 based on S. nigra 16S rDNA sequence (Data not shown). The same approach of multiple alignments was applied to $S$. albogriseolus strain BA2 and S. albogriseolus which showed 9 nt mismatches located at potions 185, 193, 199, 202, 249, 308, 328, 522, and 930 based on the 16S rDNA sequence of $S$. albogriseolus (Data not shown).

The sequence identity of the two proposed novel species S. nigra strain BA1 and S. albogriseolus strain BA2 fell within the specified cutoff of $98.7 \%-99.0 \%$, in which $S$. nigra strain BA1 showed $98.8 \%$ similarity to $S$. nigra 452 and S. albogriseolus strain BA2 showed 98.9\% similarity to $S$. albogriseolus NRRL B-1305 based on the query sequence length during comparison against other prokaryotic species in EzBiocloud. In addition to molecular evidence above, S. nigra strain BA1 (HGS6-1) can be differentiated from its closely related species $S$. nigra by morphological characteristics in which it gave pale blue pigmented spores on MSF and yellow pigmented mycelia on TSA against greyish blue spores and white mycelia for S. nigra. On the other hand, S. albogriseolus strain BA2 (HGS19-3) showed pale brown spores on MSF and grey mycelia on TSA compared with its closely related species $S$. albogriseolus which gives grey spores on MSF and white mycelia on TSA. Both proposed new species were isolated from house garden soil and incubated for 5 days at $28^{\circ} \mathrm{C}$ during morphological characteristics.

\subsection{GenBank accession number}

The nucleotide sequence of $S$. nigra strain BA1 and $S$. albogriseolus strain BA2 were deposited in GenBank with accession numbers MT239403 and MT239401, respectively.

\subsection{Phylogenetic tree analysis}

To coin a phylogenetic tree of Streptomyces nigra strain BA1, 16S rRNA gene sequence was aligned with homologous of fifty different species of Streptomyces using multiple sequence alignment command in MEGA X software. The resulting file was used to build up a neighbor-joining tree (see Figure 6).

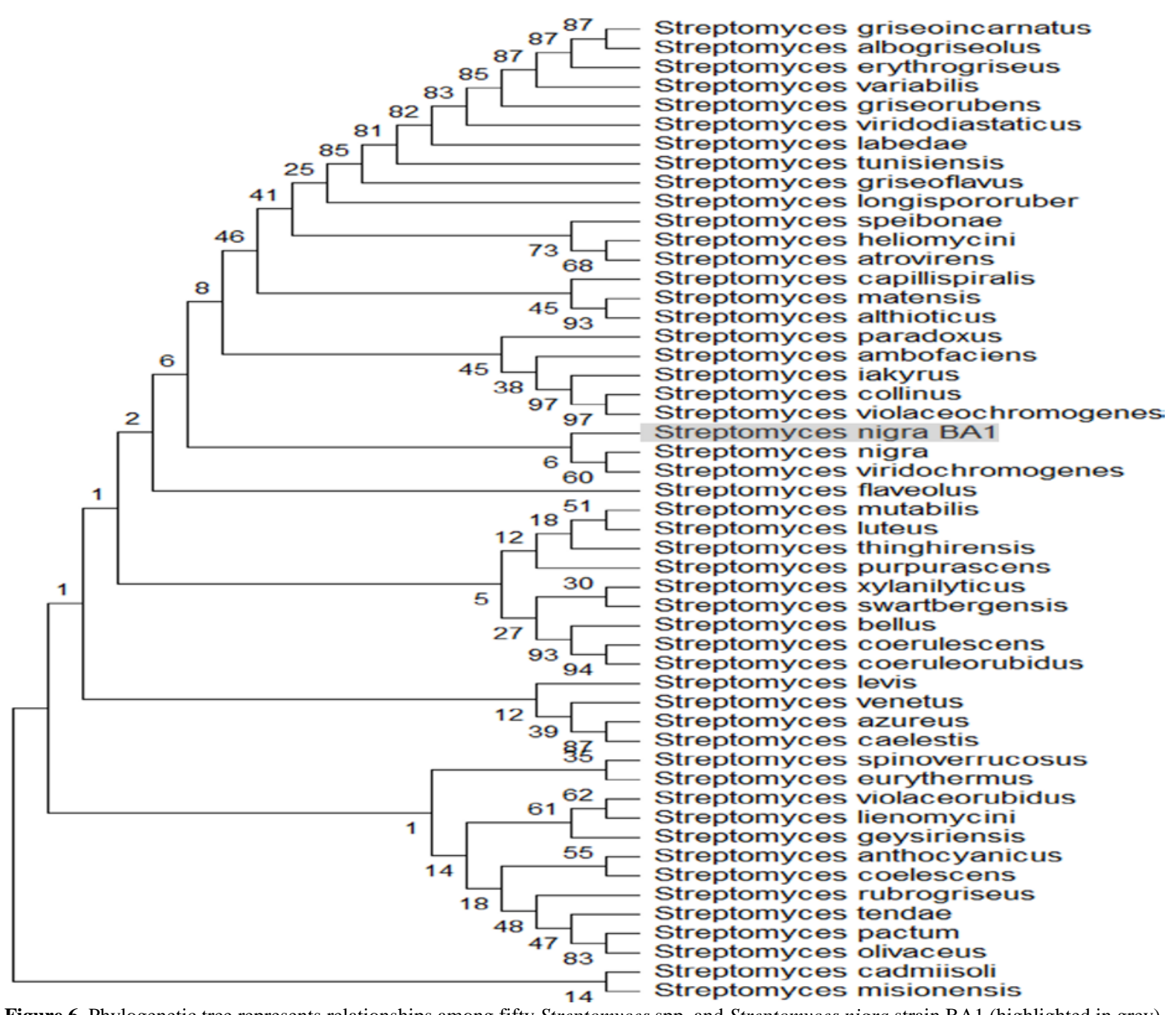

Figure 6. Phylogenetic tree represents relationships among fifty Streptomyces spp. and Streptomyces nigra strain BA1 (highlighted in grey) with based on 682bp nucleotide of 16S rRNA gene that positioned 154-836 based on S. nigra 16s rRNA. Numbers above nodes represent bootstrap values, the greater values give stronger support for the nodes. The proposed new species are highlighted in grey. 
The partial sequence of the $16 \mathrm{~S}$ rRNA gene of $S$. nigra strain BA1 was found to be reasonably in strong relation with $S$. nigra and $S$. viridochromogenes which was supported by $60 \%$ bootstrap replicates. These results support what has been detected from the 16S-based ID database (Yoon et al., 2017), which revealed that the closest species to $S$. nigra strain BA1 is $S$. nigra in terms of nucleotide sequence similarity (98.8\%) followed by $S$. viridochromogenes with $98.5 \%$ similarity. S. nigra strain BA1 has seven unique nucleotides at the following positions of its $16 \mathrm{~S}$ rDNA sequence compared to $S$. nigra: $155(\mathrm{~A} \rightarrow$ gap $), 166(\mathrm{C} \rightarrow \mathrm{T}), 173(\mathrm{~A} \rightarrow \mathrm{G}), 193(\mathrm{C} \rightarrow \mathrm{T}), 202$ $(\mathrm{C} \rightarrow \mathrm{T}), 308(\mathrm{C} \rightarrow \mathrm{G}), 328(\mathrm{C} \rightarrow \mathrm{T})$ and $502(\mathrm{~A} \rightarrow \mathrm{C}) . \quad \mathrm{A}$ weaker relationship was found between $S$. nigra strain BA1 and the last thirteen species which were $S$. coelescens, S. atrovirens, S. speibonae, S. thinghirensis, S. luteus, S. xylanilyticus, S. venetus, S. geysiriensis, S. heliomycini, S. anthocyanicus, S. mutabilis and $S$. capillispiralis with $97.5 \%$ similarity to $S$. nigra strain BA1 16S rDNA sequence.

A neighbor-joining tree was carried out between Streptomyces albogriseolus strain BA2 and homologous of fifty different species of Streptomyces using MEGA X software to obtain the taxonomic position of $S$. albogriseolus strain BA2 (Figure 7).

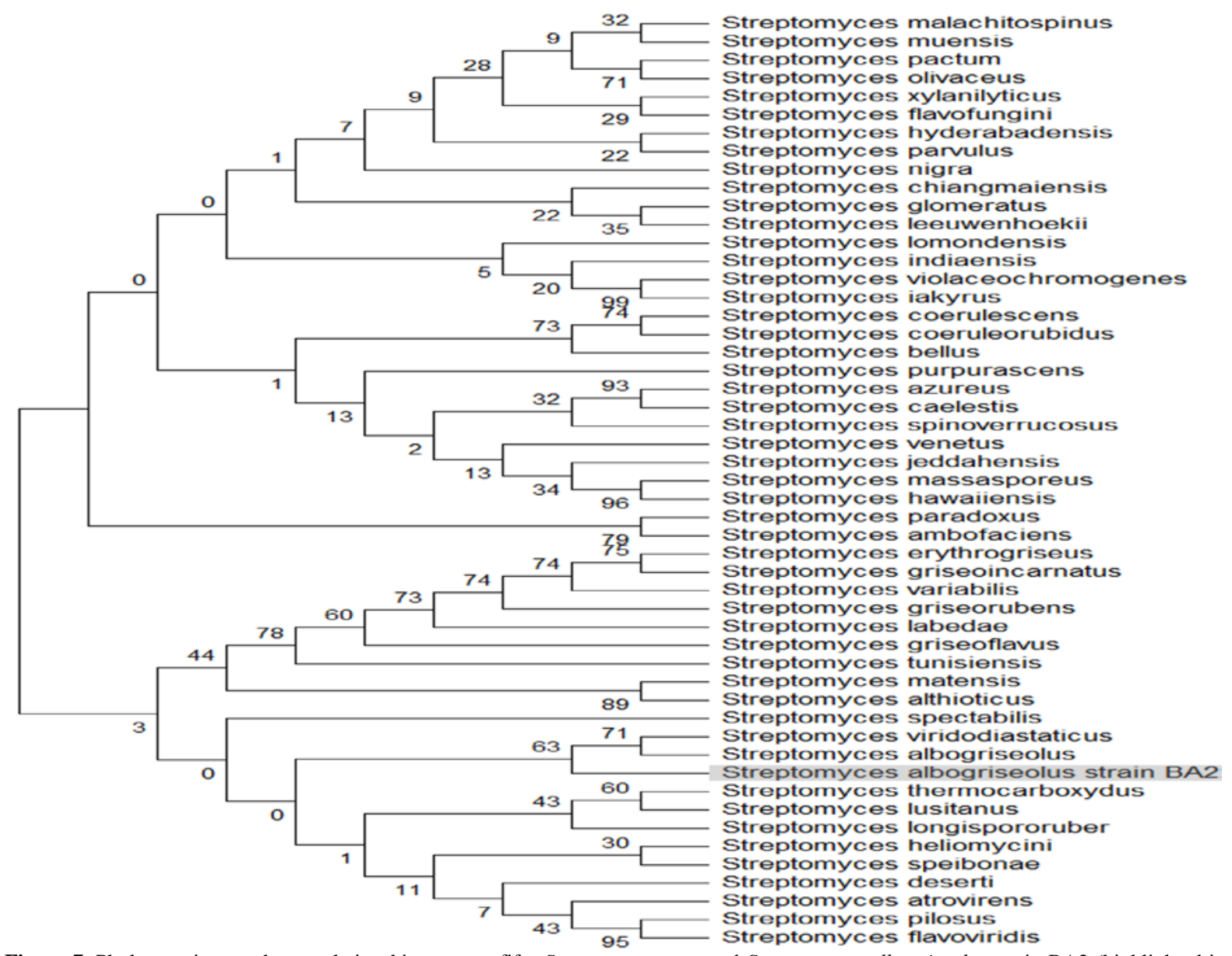

Figure 7. Phylogenetic tree shows relationships among fifty Streptomyces spp. and Streptomyces albogriseolus strain BA2 (highlighted in grey) based on 856bp nucleotide of 16S rRNA gene that positioned 167-1022 based on S. albogriseolus 16S rRNA. Numbers above nodes represent bootstrap values, the greater values give stronger support for the nodes.

It was found through comparing the $16 \mathrm{~S}$ rDNA partial sequence of $S$. albogriseolus strain BA2 with its homologous that the strongest relation formed with $S$. albogriseolus and S. viridodiastaticus supported by $63 \%$ bootstrap. A weaker association was shaped with $S$. caelestis, S. azureus, S. malachitospinus, $S$. chiangmaiensis, S. jeddahensis and S. paradoxus with a bootstrap of $0 \%$. These results are in line with what has been detected from the 16S-based ID database (Yoon et al., 2017), which revealed that the closest species to $S$. albogriseolus strain BA2 is $S$. albogriseolus and $S$. viridodiastaticus with $98.9 \%$ similarity and less similarity (97\%) was found with last six Streptomyces spp. that mentioned above. S. albogriseolus strain BA2 has nine unique nucleotides at the following positions compared to the closest species of Streptomyces (S. albogriseolus) based on the phylogenetic tree position and percentage of 16s rDNA similarity: $185(\mathrm{~A} \rightarrow \mathrm{C}), 193 \quad(\mathrm{C} \rightarrow \mathrm{T}), 199$ $(\mathrm{C} \rightarrow \mathrm{T}), 202 \quad(\mathrm{C} \rightarrow \mathrm{T}), \quad 249 \quad(\mathrm{~A} \rightarrow \mathrm{T}), \quad 308 \quad(\mathrm{C} \rightarrow \mathrm{G}), \quad 328$ $(\mathrm{C} \rightarrow \mathrm{T}), 522(\mathrm{C} \rightarrow \mathrm{T})$ and $930(\mathrm{C} \rightarrow \mathrm{T})$.

3.7. Antibacterial Activity of S. nigra strain BA1 and S. albogriseolus strain BA2 Secondary Metabolites

Secondary metabolites of $S$. nigra strain BA1 and $S$. albogriseolus strain BA2 showed antimicrobial activity against staphylococcus aureus and E.coli (Figure 8, Panels C and D); however, S. coelicolor strain L646 showed less inhibition ability against E.coli (Figure 8, Panel A). 


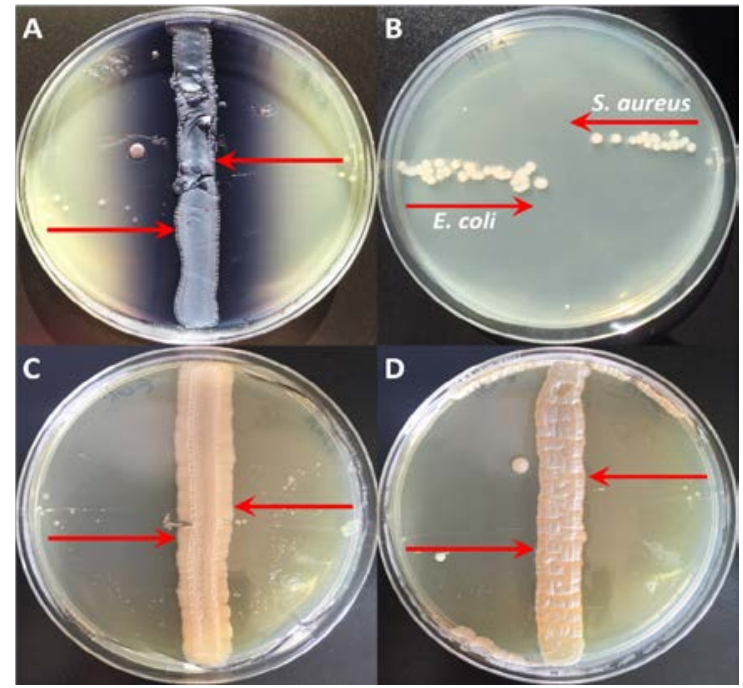

Figure 8. Antibacterial activity of Streptomyces spp. Panels A and $\mathbf{B}$ serve as positive and negative controls, respectively. S. coelicolor strain L646 was used in panel A and no Streptomyces spp. were used in panel B, it just streaked out with the tested bacteria as shown. Panels $\mathbf{C}$ and $\mathbf{D}$ represent the antibacterial activity of S. nigra strain BA1 and $S$. albogriseolus strain BA2 against E. coli (left-hand side) and Staphylococcus aureus (righthand side), respectively. The red arrows indicate the direction of inoculated bacteria toward the midline of grown Streptomyces spp.

The antibacterial inhibition activities of current Streptomyces spp. isolates can be identified by doing mode of action studies on purified or semi-purified extracts (Imai et al., 2015).

\section{Conclusion}

Morphological characterisation, biochemical test, partial 16S rDNA sequencing and phylogenic analysis were pronounced as two new candidate species of Streptomyces which were distinctive from their most closely related species. Therefore, HGS6-1 and HGS19-3 isolates are considered to serve as novel species for which the name Streptomyces nigra strain BA1 and Streptomyces albogriseolus strain BA2 proposed, respectively. Inhibition of E. coli and Staphylococcus aureus growth by secondary metabolites produced by the proposed novel Streptomyces species introduced strong evidence that they possess small molecules of medically important activity. Further work needs to be done on these two proposed novel species to identify their bioactive compounds then use them in the development of new therapeutic agents.

\section{Acknowledgements}

The authors would like to thank the Department of Medical Microbiology/ Faculty of Science and Health/ Koya University and Science and Health Research center (where the work was done) for their support.

\section{References}

Abdullah BS, Khailany RA, Muhammad HH and Hamad MI. 2017. Molecular Identification and Evolutionary Relationship of the New Record Callistethus sp. 7VF-2014 (Coleoptera: Scarabaeidae: Reutelinae) in North of Iraq. Jordan J Biol Sci., 10(1): 33-36.
Adebola A, Ewulo B and Arije D. 2017. Effects of Different Animal Manures on Soil Physical and Microbial Properties. Appl Trop Agric., 22(1): 128-133.

Adegboye MF and Babalola OO. 2012. Taxonomy and ecology of antibiotic producing actinomycetes. Afr J Agric Res., 7(15): 22552261.

Alabi OS, Koleoso OB and Abiala AM. 2019. Antimicrobial screening and GC-MS analysis of bioactive compounds from strains of Pseudomonas aeruginosa isolated from poultry fecal littered soil in Ibadan, Nigeria. Nig J Pure \& Appl Sci., 32(1): 3347- 3357.

AL-Hulu SM, AL-Charrakh AH and Jarallah EM. 2011. Antibacterial activity of Streptomyces gelaticus isolated from Iraqi soils. Med J Babylon, 8(3): 404-411.

Al-Saadi A, Majid N and Jaralla E. 2013. Isolation and Identification of Streptomyces from different sample of soils. JBMS, 1: 31-36.

Ambarwati A, Sembiring L and Soegihardjo C. 2012. Antibiotic produced by streptomycetes associated with rhizosphere of purple nutsedge (Cyperus rotundus L.) in Surakarta, Indonesia. Afr $J$ Microbiol Res., 6(1): 52-57.

Anandan R, Dharumadurai D and Manogaran G. 2016. An Introduction to Actinobacteria. In: Dharumadurai D and $\mathrm{Yi} \mathrm{J}$ (Eds). Actinobacteria - Basics and Biotechnological Applications.IntechOpen Publishers, India pp.1-37.

Arifuzzaman M, Khatun M and Rahman H. 2010. Isolation and screening of actinomycetes from Sundarbans soil for antibacterial activity. Afr J Biotechnol., 9(29): 4615-4619.

Awad HM and Germoush MO. 2017. Molecular and morphological identification of Streptomyces sp. NRC-88 nova species as $\beta$-lactamase inhibitor for pharmaceutical application. Asian J Pharm Clin Res., 10(10): 376-383.

Chen Y, Zhou D, Qi D, Gao Z, Xie J and Luo Y. 2018. Growth promotion and disease suppression ability of a Streptomyces sp. CB-75 from banana rhizosphere soil. Front Microbiol., 8: 2704.

Chevrette MG, Carlson CM, Ortega HE, Thomas C, Ananiev GE, Barns KJ, Book AJ, Cagnazzo J, Carlos C and Flanigan W. 2019. The antimicrobial potential of Streptomyces from insect microbiomes. Nat Commun., 10(1): 516-527.

Fatima A, Aftab U, Shaaban KA, Thorson JS and Sajid I. 2019. Spore forming Actinobacterial diversity of Cholistan Desert Pakistan: Polyphasic taxonomy, antimicrobial potential and chemical profiling. BMC Microbiol., 19(1): 1-17.

Flärdh K and Buttner MJ. 2009. Streptomyces morphogenetics: dissecting differentiation in a filamentous bacterium. Nat Rev Microbiol., 7(1): 36-49.

George J, Arunachalam R, Paulkumar K, Wesely E, Shiburaj S and Annadurai G. 2010. Characterization and phylogenetic analysis of cellulase producing Streptomyces noboritoensis SPKC1. Interdiscip Sci., 2(2): 205-212.

Hasani A, Kariminik A and Issazadeh K. 2014. Streptomycetes: characteristics and their antimicrobial activities. Int J Adv Biol Biom Res., 2(1): 63-75.

Huang X and Miller W. 1991. Lalign-find the best local alignments between two sequences. Adv Appl Math, 12: 373-381.

Imai Y, Sato S, Tanaka Y, Ochi K. and Hosaka T. 2015. Lincomycin at subinhibitory concentrations potentiates secondary metabolite production by Streptomyces spp. Appl Environ Microbiol., 81(11): 3869-3879.

Janardhan A, Kumar AP, Viswanath B, Saigopal D and Narasimha G. 2014. Production of bioactive compounds by actinomycetes and their antioxidant properties. Biotechnol Res Int., 2014: 1-8. 
Kelemen GH, Brian P, Flardh K, Chamberlin L, Chater KF and Buttner MJ. 1998. Developmental regulation of transcription of whiE, a locus specifying the polyketide spore pigment in Streptomyces coelicolor A3 (2). J Bacteriol., 180(9): 2515-2521.

Kheiralla ZH, Hewedy MAH, Mohammed HR and Darwesh OM. 2016. Isolation of pigment producing actinomycetes from rhizosphere soil and application it in textiles dyeing. Res J Pharm Biol Chem Sci., 7(5): 2128-2136.

Kim SH, Traag BA, Hasan AH, McDowall KJ, Kim B-G and van Wezel GP. 2015. Transcriptional analysis of the cell divisionrelated ssg genes in Streptomyces coelicolor reveals direct control of ssgR by AtrA. Antonie Van Leeuwenhoek, 108(1): 201-213.

Laidi RF, Abderrahmane A and Norya AH. 2013. Identification and Antibiosis of a Novel Actinomycete Strain RAF-11 Isolated From Iraqi Soil. Int J Sci: Basic Appl Res., 12(1): 141-159.

Li Y, Liu J, Díaz-Cruz G, Cheng Z and Bignell DR. 2019. Virulence mechanisms of plant-pathogenic Streptomyces species: an updated review. Microbiology, 165: 1025-1040.

Maleki H, Dehnad A, Hanifian S and Khani S. 2013. Isolation and molecular identification of Streptomyces spp. with antibacterial activity from northwest of Iran. BioImpacts, 3(3): 129-134.

Massadeh MI and Mahmoud SM. 2019. Antibacterial Activities of Soil Bacteria Isolated from Hashemite University Area in Jordan. Jordan J Biol Sci., 12(4): 503-511.

Massenssini A, Bonduki V, Melo C, Totola M, Ferreira F and Costa M. 2014. Soil microorganisms and their role in the interactions between weeds and crops. Planta Daninha, 32(4): 873-884.

Minas W, Bailey JE and Duetz W. 2000. Streptomycetes in microcultures: Growth, production of secondary metabolites, and storage and retrieval in the 96-well format. Antonie Van Leeuwenhoek, 78(3-4): 297-305.

Murray J, Salih T and Tucker N. 2019. The emergent properties of streptomyces observed during co-culture and the genomic and morphological characterisation of a Streptomyces lydicus strain. Access Microbiology, 1(1A): 115-120.

Reddy P and Umamaheshwara RV. 2016. Mycelial and Pigmentation studies of Dibenzothiophene desulfurizing Streptomyces species isolated from oil contaminated sites. Int J Pharm Biol Sci., 11(5): 143-146.

Rintala H, Nevalainen A, Rönkä E and Suutari M. 2001. PCR primers targeting the 16S rRNA gene for the specific detection of Streptomycetes. Mol Cell Probes, 15(6): 337-347.

Romero DA, Hasan AH, Lin Yf, Kime L, Ruiz-Larrabeiti O, Urem M, Bucca G, Mamanova L, Laing EE and van Wezel GP. 2014. A comparison of key aspects of gene regulation in Streptomyces coelicolor and Escherichia coli using nucleotide-resolution transcription maps produced in parallel by global and differential RNA sequencing. Mol Microbiol., 94(5): 963-987.

Salerno P, Persson J, Bucca G, Laing E, Ausmees N, Smith CP. and Flardh K. 2013. Identification of new developmentally regulated genes involved in Streptomyces coelicolor sporulation. BMC Microbiol., 13(1): 281-299.
Saitou N and Nei M. 1987. The neighbor-joining method: a new method for reconstructing phylogenetic trees. Mol Biol Evol., 4(4): 406-425.

Schlaberg R, Simmon KE and Fisher MA. 2012. A Systematic Approach for Discovering Novel, Clinically Relevant Bacteria. Emerg Infect Dis., 18 (3): 422-430.

Shepherd MD, Kharel MK, Bosserman MA and Rohr J. 2010. Laboratory maintenance of Streptomyces species. Curr Protoc Microbiol., 18(1): 10E.1.1-10E.1.8.

Singh V, Haque S, Singh H, Verma J, Vibha K, Singh R, Jawed A and Tripathi C. 2016. Isolation, screening, and identification of novel isolates of Actinomycetes from India for antimicrobial applications. Front Microbiol., 7: 1921.

Sottorff I, Wiese J, Lipfert M, Preußke N, Sönnichsen FD and Imhoff JF. 2019. Different secondary metabolite profiles of phylogenetically almost identical Streptomyces griseus strains originating from geographically remote locations. kimMicroorganisms, 7(6): 166.

Stackebrandt E. and Ebers J. 2006. Taxonomic parameters revisited: tarnished gold standards. Microbiol Today, 8(4): 6-9.

Tamura K, Peterson D, Peterson N, Stecher G, Nei M and Kumar S. 2011. MEGA5: molecular evolutionary genetics analysis using maximum likelihood, evolutionary distance, and maximum parsimony methods. Mol Biol Evol., 28(10): 2731-2739.

Thompson JD, Higgins DG and Gibson TJ. 1994. CLUSTAL W: improving the sensitivity of progressive multiple sequence alignment through sequence weighting, position-specific gap penalties and weight matrix choice. Nucleic Acids Res., 22(22): 4673-4680.

Vartoukian SR, Palmer RM and Wade WG. 2010. Strategies for culture of 'unculturable' bacteria. FEMS Microbiol Lett., 309(1): $1-7$.

Walker T, Stapleton P and Gibbons S. 2019. Identification of novel antimicrobial-producing bacteria from an ancient water source by Oxford Nanopore Whole Genome Sequencing and Natural Product Chemistry. Access Microbiology, 1(1A).

Westhoff S, Otto SB, Swinkels A, Bode B, van Wezel GP and Rozen DE. 2020. Spatial structure increases the benefits of antibiotic production in Streptomyces*. Evolution, 7(1): 179-187.

Xu X, Liu W, Tian S, Wang W, Qi Q, Jiang P, Gao X, Li F, Li H and $\mathrm{Yu} \mathrm{H}$. 2018. Petroleum hydrocarbon-degrading bacteria for the remediation of oil pollution under aerobic conditions: a perspective analysis. Front Microbiol., 9: 2885.

Yoon S-H, Ha S-M, Kwon S, Lim J, Kim Y, Seo H and Chun J. 2017. Introducing EzBioCloud: a taxonomically united database of 16S rRNA gene sequences and whole-genome assemblies. Int $J$ Syst Evol Microbiol., 67(5):1613-1617.

Yücel S and Yamaç M. 2010. Selection of Streptomyces isolates from Turkish karstic caves against antibiotic resistant microorganisms. Pak J Pharm Sci, 23(1):1-6. 